Prace Literackie LX

Wrocław 2021

https://doi.org/10.19195/0079-4767.60.6

\author{
ŁUKASZ PIASKOWSKI \\ ORCID: 0000-0002-3528-4301 \\ Uniwersytet Wrocławski
}

\title{
Widmo Chopina krąży po Warszawie
}

Recenzja: Michał Kuziak, Pejzaż myśli. Warszawa Chopina i początek polskiej nowoczesności, Narodowy Instytut Fryderyka Chopina, Warszawa 2020, ss. 246

W 2018 roku Narodowy Instytut Fryderyka Chopina powołał do życia nową serię wydawniczą o jakże lapidarnej i wiele mówiącej nazwie „Chopin: Konteksty". Celem tej inicjatywy jest stworzenie bogatego repozytorium tekstów dotyczących życia i twórczości Fryderyka Chopina, ale takich, w których muzykologiczny punkt widzenia pełni funkcję pomocniczą, nie zaś fundamentalną. Muzykologiczna perspektywa zostaje zredukowana na rzecz innego rodzaju metodologii: literaturoznawczej, kulturoznawczej, historycznej, antropologicznej i innych. Warto wskazać ponadto na przeznaczenie wydawanej serii. Ma ona bowiem charakter nie tylko naukowy, lecz także popularyzatorski. Do dziś pod egidą serii opublikowano sześć książek: Anny Adamusińskiej-Tasak o teatrach warszawskich, do których zwykł chadzać Chopin w czasach swej młodości; dwie książki Andrzeja Fabianowskiego - jedna to monografia poświęcona Towarzystwu Iksów, a więc słynnej grupie klasycystycznych krytyków teatralnych, druga zaś to próba rekapitulacji i nowego odczytania relacji między Chopinem a Cyprianem Norwidem; książka Magdaleny Dziadek poświęcona dziewiętnastowiecznym monografiom Chopina oraz wznowiona po 100 latach od pierwszej publikacji książka Ferdynanda Hoesicka, w której autor zamieścił wspomnienia ludzi pamiętających zarówno Chopina, jak i dawną dziewiętnastowieczną Warszawę ${ }^{1}$. Ostatnią jak dotąd, a zatem szóstą książką omawianej serii, jest Pejzaż myśli. Warszawa Chopina i poczatek polskiej nowoczesności Michała Kuziaka. Wymieniony zespół autorów dowodzi, że jak do tej pory seria dotycząca kontekstów życia Chopina ma wymiar muzykologiczno-literaturoznawczy. Jakie będą jej dalsze losy — rozstrzygną za-

1 Zob. A. Adamusińska-Tasak, Scena warszawska oczami Fryderyka Chopina, Warszawa 2018; A. Fabianowski, Towarzystwo Iksów, Warszawa 2019; idem, Sonata Norwidowska, Warszawa 2019; M. Dziadek, O polskich biografiach Chopina w XIX wieku, Warszawa 2019; F. Hoesicka, Warszawa. Luźne kartki z przeszłości Syreniego Grodu, red. M. Karpińska, Warszawa 2020. 
pewne kolejne publikacje. Wróćmy jednak do książki Kuziaka, która jest głównym przedmiotem naszego zainteresowania.

Przedsięwzięcie autora jest niezwykle interesujące i cenne, przede wszystkim dlatego, że w obliczu istniejącej już literatury dotyczącej Warszawy niełatwo temat ten odświeżyć. Istnieje bogata bibliografia „warszawska”. Począwszy od książek, które pisano już w XIX wieku², a skończywszy na wielorakich ujęciach dziewiętnastowiecznych - zarówno przedwojennych ${ }^{3}$, jak i powojennych ${ }^{4}$. O Warszawie pisano z różnych perspektyw: historycznej, kulturoznawczej, muzykologicznej, literaturoznawczej, antropologicznej itp. Równie wdzięcznym tematem książek były związki Chopina z Warszawą ${ }^{5}$ a także wszelkie wariacje na temat, takie jak związki Chopina z Warszawą literacką ${ }^{6}$ czy też z muzyczną ${ }^{7}$. Trzeba jednocześnie podkreślić, że niemal każda książka poświęcona osobie kompozytora, może poza analizami muzykologicznymi zorientowanymi na metodologie formalistyczne ${ }^{8}$, zawiera rozdział poświęcony życiu Chopina w Warszawie. Biografizm w książkach poświęconych Chopinowi jest w zasadzie zwyczajowy. Miał on wręcz charakter interwencyjny. Jak wiemy bowiem, Chopin był w połowie Francuzem, toteż kryterium polskości posługiwano się w krytyce muzycznej od samego początku, by podkreślić mocne związki łączące kompozytora z ojczyzną. W tej sytuacji łączenie Chopina z Warszawą było czymś najoczywistszym. Zdecydowanie ostało się ono w polskiej refleksji nad twórczością kompozytora, czego najlepszym dowodem jest kolejny wysyp książek i publikacji poświęconych niejako geografii i topografii chopinowskiej. W 2010 roku, a zatem w dwusetlecie urodzin Chopi-

2 Autorem klasycznych już prac był Kazimierz Władysław Wóycicki. Zob. K.W. Wóycicki, Kawa literacka w Warszawie (r. 1829-1830), Warszawa 1873; idem, Warszawa i jej społeczność w poczatkach naszego stulecia, Warszawa 1875.

3 Wymienić można przynajmniej kilka: F. Hoesick, Chopin. Życie i twórczość, t. 1. Warszawa 1810-1831, Warszawa 1910; L. Rydel, Warszawa i jej dzieje kulturalne i wojenne, Kraków 1915; F. Hoesick, Warszawa. Luźne kartki z przeszłości Syreniego Grodu, Warszawa 1920; J. Siemieński, Warszawa w dziejach Polski, Warszawa [ok. 1929].

${ }^{4}$ Najbardziej znaczące dokonania historyczne i literaturoznawcze: A. Kowalska, Warszawa literacka w okresie przełomu kulturalnego 1815-1822, Warszawa 1961; A. Kowalczykowa, Warszawa romantyczna, Warszawa 1987.

5 Zob. np. Warszawa miasto Chopina, red. Z. Jachimecki et al., Warszawa 1950; T. Frączyk, Warszawa młodości Chopina, Kraków 1961; Z. Jeżewska, Warszawskim szlakiem Chopina, Warszawa 1979; J. Prosnak, Fryderyk Chopin. Żelazowa Wola. Warszawa, Warszawa 1977.

${ }^{6}$ Wciąż jedną z cenniejszych książek w tym obszarze jest Franciszka Germana, Chopin i literaci warszawscy, Kraków 1960.

7 Zob. F. German, Muzycy warszawscy okresu młodości Chopina, Katowice 1977. A także ważna książka Haliny Goldberg z ostatnich lat. Zob. H. Goldberg, O muzyce w Warszawie Chopina, przeł. M. Albán Juárez, K. Stępień-Kutera, Warszawa 2016.

8 Tu naczelnymi przykładami mogą być klasyczne już książki Józefa Michała Chomińskiego czy Zofii Lissy. Zob. Z. Lissa, Studia nad twórczością Fryderyka Chopina, Kraków 1970; J.M. Chomiński, Chopin, Kraków 1978. 
na, owo wzmożenie osiągnęło punkt kulminacyjny. Wydawano nie tylko książki ${ }^{9}$, ale nakręcono też okolicznościowy film ${ }^{10}$, założono specjalne ławki odgrywające utwory kompozytora, stworzono też aplikację ${ }^{11}$, dzięki której można zwiedzić Warszawę śladem Chopina.

Tematyka kontekstowej w swym charakterze książki Kuziaka jest na pierwszy rzut oka nader wyeksploatowana; podkreślmy też, że wymieniłem jedynie książki, druki zwarte, nie zwracając szczególnej uwagi na artykuły podobnemu tematowi poświęcone. Warto jednak wskazać na jedną istotną kwestię. Bardzo ważną cechą wszystkich dzieł książkowych, w których ukazywano, mniej lub bardziej szczegółowo, warszawskie życie polskiego kompozytora, jest ich „,chopinocentryczność". Ujęciom tym towarzyszy perspektywa podmiotowa, przez której pryzmat rozpatrywano miasto rozumiane jako przestrzeń, w której rozwijał się talent muzyczny, a także romantyczny światopogląd. Kuziak proponuje inną metodę: przesuwa Chopina na dalszy plan, umniejsza jego udział w opowiadanej historii. Efektem takiej operacji jest ustawienie Chopina w kontekście, przy czym ów kontekst jest niejako pierwszym planem. Cel, jaki w ten sposób osiąga autor, jest bardzo czytelny: aby lepiej zrozumieć Chopina i to, kim był, należy bliżej przyjrzeć się zmieniającej się podówczas rzeczywistości, a zwłaszcza rodzącej się polskiej nowoczesności ${ }^{12}$

Z podobnych przesłanek wychodził między innymi Henryk Opieński w artykule Czy Chopin jest romantykiem?, napisanym już w 1937 roku. Jak pisał sam autor: „zadaniem moim będzie ustalenie stosunku Chopina do tej ideologii rozpoczynającego się XIX wieku"13. Opieński twierdzi, że Chopin jest kompo-

9 Zob. np. P. Mysłakowski, A. Sikorski, Fryderyk Chopin. Korzenie, Warszawa 2009; J. Miziołek, Śladami Chopina po Uniwersytecie Warszawskim. 200-lecie urodzin geniusza fortepianu (1810-2010), Warszawa 2010; C. Czapliński, Śladami Chopina w Warszawie i na Mazowszu, Płock 2010; B. Niewiarowska, Warszawa Fryderyka Chopina, wstęp K. Mórawski, W. Młotkowski, Warszawa 2010; P. Mysłakowski, Warszawa Chopinów. Warszawskie adresy Chopinów na podstawie źródeł ustalone, oprac. kartogr. P.E. Weszpiński, Warszawa 2012; J. Miziołek, H. Kowalski, Uniwersytet Warszawski i młody Chopin, Warszawa 2013; M. Wąsowski, Fryderyk w Pałacu, Warszawa 2018.

10 Film o znamiennym tytule Warszawa Chopina został nakręcony z okazji Roku Chopinowskiego 2010. Producentem filmu było Miasto Stołeczne Warszawa, reżyserem Kordian Piwowarski, autorkami zaś scenariusza Anna Piwowarska oraz Amy Drozdowska. Osobno warto wyróżnić inicjatywy Instytutu Fryderyka Chopina, który na swoim kanale YouTube umieścił chociażby takie filmy edukacyjne, jak: Polska Chopina. Młody warszawiak w podróży czy Młodość Fryderyka Chopina.

11 Więcej na ten temat można przeczytać na wydawanym przez Instytut Adama Mickiewicza portalu Culture.pl. Zob. [b.a.], Spacer „Z Chopinem po Warszawie”, https://culture.pl/pl/artykul/ spacer-z-chopinem-po-warszawie (dostęp: 19.07.2021).

12 Tematykę początków dziewiętnastowiecznej nowoczesności poruszał już autor w zredagowanej przez siebie książce: Romantyzm i nowoczesność, red. M. Kuziak, Kraków 2009. Przywołuję ją głównie dlatego, że wiele tropów i intuicji z tej pracy zostało zastosowanych także i w omawianej w tej recenzji propozycji.

13 H. Opieński, Czy Chopin jest romantykiem?, „Chopin” 1937, nr 2, s. 57. 
zytorem „pozaepokowym”, a jego twórczości towarzyszy uniwersalizm. Jedną z zasadniczych przyczyn tego stanu rzeczy jest właśnie okres warszawski, który jednoznacznie odcisnął na kompozytorze piętno. Postać Chopina jest doskonałym materiałem badawczym; wspaniałym wręcz przykładem do analiz. Jeśli trzymać się wykładni Opieńskiego, można zadać sobie pytanie: w jaki sposób nowoczesność, $\mathrm{z}$ jednej strony w wydaniu klasycystyczym, a z drugiej — w romantycznym, rozwijała osobowość kompozytora? Była ona wszak w istocie złożona. Jak twierdzi zaś Kuziak, nieco w duchu Opieńskiego, romantyzm polski był kształtowany w atmosferze zarówno modernizacyjnej, jak i konserwatywnej. Istotny w tej sytuacji jest, co autor zauważył zgoła gdzieś indziej, fakt, że do badania początków polskiego romantyzmu warto zastosować metodę, którą Kuziak nazwał „rekonstrukcją samowiedzy romantycznej”, związaną z doświadczaną przez romantyków nowoczesnością ${ }^{14}$. Tę samą procedurę usiłuje autor, jak się wydaje, przeprowadzić w książce poświęconej Warszawie Chopina. Istotne wydaje się zatem zrekonstruowanie kontekstu, który doprowadzi nas z kolei do rekonstrukcji samowiedzy Chopina, pozostającego pod wpływem tej charakterystycznej dla polskiego środowiska, niemalże sprzecznej wewnętrznie nowoczesności.

Sam Kuziak określa obecność Chopina w książce jako „widmową?. Można przez to rozumieć, że jako czytelnicy usiłujemy zrozumieć kontekst życia Chopina, nie ustawiając go jednak jako epicentrum myśli i dyskursu. Założeniem pracy badawczej jest bowiem zrozumienie, jakie istotne elementy warszawskiej rzeczywistości mniej lub bardziej wpłynęły na kształtowanie się Chopina - nie tylko jako muzyka, lecz także jako człowieka, z bagażem budujących doświadczeń, które determinują wielorakie poziomy egzystencji. Bardzo istotne jest dla Kuziaka spojrzenie na Warszawę jak na ludzki organizm, w którym wszystkie elementy są z sobą nierozerwalnie połączone i wzajemnie od siebie zależne. Ten złożony byt określa autor jako kosmos, w którego obrębie kształtowały się losy młodego Fryderyka — przypomnijmy bowiem, że lata 1810-1830, a więc okres, który interesuje Kuziaka najbardziej, to pierwsze 20 lat życia kompozytora.

Książka, co można podkreślić na marginesie, wydana jest ze starannością, na dobrym papierze, zawiera wiele ilustracji z epoki, które wydrukowano w kolorze i bardzo wysokiej jakości. Samo obcowanie z książką jest już dla czytelnika przyjemne. Wracając jednak od dygresji dotyczącej formy — do treści, warto przyjrzeć się układowi pracy. Autor podzielił książkę na trzy części, które poprzedza krótki metodologiczny wstęp. Zasadnicza część merytoryczna wzbogacona została o dwa skorowidze: osób i dzieł oraz miejsc i instytucji. Pierwsza merytoryczna część pracy, nie licząc rzecz jasna wstępu, zatytułowana jest Miasto i ludzie; druga - Instytucje $i$ ludzie, trzecia zaś — Myśli i ludzie. Widzimy więc, że autor przyjął metodę metaforycznego kontrapunktu, którego głosem stałym są ludzie, a zatem perspektywa antropologiczna, a głosami pozostającymi w relacji kontra-

${ }^{14}$ M. Kuziak, Romantyzm i nowoczesność?, [w:] Romantyzm i nowoczesność..., s. 11. 
punktycznej: miasto, instytucje i myśli. Kuziak zwraca więc uwagę na przestrzeń, zorganizowaną za sprawą istniejących w jej obrębie instytucji, które to z kolei są instrumentalizowane i napędzane przez myśl. Innymi słowy poznajemy Warszawę Chopina od strony ludzkiej, instytucjonalnej i intelektualnej (na co składają się rzecz jasna przede wszystkim bloki światopoglądowe, często wzajemnie się zwalczające). Zanim jednak przejdę do omówienia każdego z tych dużych rozdziałów, warto chwilę zatrzymać się przy wstępie. Autor od samego początku informuje nas, że traktuje swoją pracę jako esej naukowy (s. 9). Widoczne jest to przede wszystkim w swobodzie operowania językiem, który jest komunikatywny, a także dyskursem często nacechowanym stylistycznie. Doskonałym tego przykładem są stosowane metafory, na przykład laboratorium, kosmosu czy wyspy, które czynią pracę nader obrazową i strawną nawet dla mniej wyrobionego czytelnika. Jakie są więc główne założenia książki? Autor pisze o nich wprost: „Podstawą książki jest założenie istnienia, a raczej kształtowania się środowiska intelektualno-kulturowego, swoistego kosmosu — tygla, konstelacji — myśli” (s. 10). Przy czym, jak thumaczy autor, sytuacja polska jest o tyle specyficzna, że nowoczesny typ kultury tworzono z jednej strony z poczucia zamknięcia pewnego etapu wraz z upadkiem państwa, z drugiej zaś - pod naciskiem sił, które romantyczny typ nowoczesności poprzedzały, a zatem klasycyzm stanisławowski. Kuziak, używając pojęć cywilizacji i kultury, wyjaśnia ponadto, w jaki sposób formułowały się modele nowoczesności w zachodniej Europie. Cywilizacja jest pojęciem stworzonym na gruncie francuskim, związana była z myślą techniczno-materialistyczną, mającą za cel stworzenie szczęśliwego społeczeństwa, którego zasadniczym napędem ideowym był postęp. Rewersem tej idei było barbarzyństwo, które prędko skojarzono ze Wschodem właśnie - a zatem i z Polską również (s. 11). Pojęcie kultury, jak tłumaczy Kuziak, wywodzi się zaś z tradycji oświecenia niemieckiego, głównie z myśli Immanuela Kanta. Najistotniejszą konsekwencją tej filozofii było przeciwstawienie świata ludzkiego, opartego na rozumie i wolności, światu natury (s. 11). Owe dwa pojęcia miały znaczenie dla rozwoju polskiej nowoczesności. Kuziak, powtarzając za Ryszardem Przybylskim, używa zręcznej metafory „testamentu", który zostawili swoim potomkom twórcy polskiego oświecenia, zaczytani w zachodnich pismach filozoficznych. Istotną kwestią pozostaje także, iż początek XIX wieku współtworzyły dwie przynajmniej orientacje „duchowe”; jedna związana z postoświeceniową postawą naukową, druga zaś - ze światem poezji, ducha i religii. Jak jednak przekonuje autor, trudno opisać te światy w zupełnej izolacji, ponieważ kultura początku wieku przypominała tygiel, w którego obrębie różne ścieżki myśli przecinały się i współwystępowały (s. 14).

Jak natomiast Kuziak podstawowo definiuje nowoczesność? Posłuchajmy autora: „Pisząc o nowoczesności — i najczęściej wymiennie [...] o modernizacji — mam na myśli szerokie rozumienie tego terminu, związane z rozwojem wiedzy i techniki, przemianami społecznymi i politycznymi, ekonomicznymi, obyczajowymi oraz mentalnymi, a także formułą sztuki” (s. 15). Chodzi zatem o radykalne 
przekierowanie wektora egzystencjalnego i poznawczego na „nowość, teraźniejszość i przyszłość" - a zatem nowoczesność rozumianą jako zasadniczą zmianę ludzkiego życia, więcej — zdecydowane dążenie do tej zmiany. Motorem tych zmian miał być rzecz jasna człowiek, a narzędziem - ludzki rozum. Ten modelowy kształt nowoczesności nabrał w kontekście polskim nieco innego kształtu, jako że układ społeczny sprzyjał postawom zdecydowanie konserwatywnym. Dlatego też, jak powiada Kuziak, polski początek XIX wieku to czasy „,mocno eklektyczne, stanowiące efekt fuzji [...] światopoglądu szlacheckiego [...] i kształtującego się światopoglądu mieszczańskiego" (s. 16). Dochodzi do zasadniczej mieszanki tego, co tradycyjnie polskie, z tym, czego rodowód jest zasadniczo oświeceniowy. Wzrasta napięcie między nauką a religijnością. Modernizacja trafiła więc na środowisko wewnętrznie ambiwalentne: „niechęć do modernizacji wykształciła się na ziemiach polskich, zanim w ogóle doszło do jakiejkolwiek modernizacji”" (s. 17). Na tym tle wyróżniała się jednak Warszawa, w której kształtowały się modele polskiej nowoczesności. Los chciał, że było to miasto, w którym dorastał Fryderyk Chopin. Istotnym metodologicznym założeniem Kuziaka jest przekonanie, że „człowiek jest nierozerwalnie i w wielowymiarowy sposób połączony z przestrzenią, w której egzystuje. Środowisko kształtuje człowieka, a ten z kolei stara się realizować swoją wolność i również ją kształtować” (s. 18). Taką właśnie przestrzenią jest miasto, tu Warszawa, w którego obrębie istnieją ludzie, istotne jednostki kształtujące jego myślowy i instytucjonalny kształt. Polska nowoczesność jest bowiem zjawiskiem zdeterminowanym przez elity umysłowe. Do istotnych założeń metodologicznych książki warto włączyć odwołania do teorii „opisu gęstego" Clifforda Geertza, którą Kuziak wykorzystuje świadomie i celowo: „Przyjęta przeze mnie perspektywa ma na celu nie tylko samą rejestrację zjawisk, lecz także ich interpretację" (s. 20). Najistotniejszym dla autora pojęciem jest rzecz jasna nowoczesność, przez której pryzmat pragnie odczytywać przeszłość. Zaczątkiem kształtowania tej nowoczesności był początek XIX wieku, dramatycznym zaś końcem, lub przerwą, wybuch powstania listopadowego. Kuziak posługuje się w książce konceptem nowoczesności „wyspowej”. Według badacza nowoczesność „w Polsce wielokrotnie wyłaniała się na pewien moment, kształtowała środowisko cywilizacyjne, kulturowe, po czym najczęściej była zatapiana albo sama tonęła". Jako zasadniczy przykład owego tonięcia podaje autor powstanie listopadowe $1830 \mathrm{roku}^{15}$.

W pierwszej części książki, zatytułowanej Miasto i ludzie, Kuziak kreśli obraz Warszawy lat 1810-1830. Stawia sobie pytanie o Warszawę rozumianą jako swoistą całość. Ambicją jest zatem spojrzenie holistyczne. Rozpoznanie Warsza-

15 Wypowiedź pochodzi z wywiadu z M. Kuziakiem przeprowadzonego przez Kingę Michalską w audycji „O wszystkim z kulturą” na antenie II Programu Polskiego Radia. Zob. K. Michalska, M. Kuziak, Warszawa czasów Chopina była wyspa nowoczesności, https://www.polskieradio. pl/8/3664/Artykul/2727860,Prof-Michal-Kuziak-Warszawa-czasow-Chopina-byla-wyspa-nowoczesnosci (dostęp: 19.07.2021). 
wy z wielu perspektyw: z punktu widzenia kulturowego, literackiego, muzycznego czy może ogólniej: intelektualnego, artystycznego i egzystencjalnego. Bardzo ważna jest jednak perspektywa myślowa kształtująca Warszawę.

Ważną metaforą, jakiej używa autor w pierwszej części książki, jest „,kosmos myśli”". W obrębie rozwijających się od końca XVIII miast tworzy się bowiem klimat intelektualny, który przyspieszył powołanie do życia idei nowoczesności, nowego typu kultury. Bardzo ważnym węzłem podziału przestrzeni staje się antynomia miasto-wieś. Miasto to tygiel różnorodności, rozwoju ludzkiej myśli, postępu, zmiany, nowości; wieś zaś — to ostoja wartości tradycyjnych i swojskich (s. 27-28). W obrębie Warszawy powstaje podobna antynomia: z jednej strony pojawiają się obrońcy dawnego postfeudalnego porządku, z drugiej zaś — reformatorzy. Kuziak określa Warszawę jako miasto pogranicza kulturowego, wymieniając kilka jego rodzajów. Przede wszystkim zauważa pograniczność między martwą dawną Rzeczpospolitą a państwami zaborczymi, przez co charakter miasta określany jest w aspekcie różnych systemów polityczno-ekonomicznych, a także kulturowych (s. 38). Warto podkreślić, że w Warszawie „,pruskiej” odżyło zdecydowanie życie muzyczne, zwłaszcza dzięki obecności w niej słynnego Ernsta Theodora Amadeusa Hoffmanna (s. 39). Działalność muzyczną podtrzymywał Józef Elsner, nauczyciel Chopina. Drugim typem pogranicza jest oscylacja między Wschodem a Zachodem (s. 40). Oznaczało to, że stolica Polski jest miastem „przejściowym, [...] w którym to, co cywilizowane, splatało się z barbarzyńskim" (s. 40). Jak thumaczy autor książki, dla Prusaków Warszawa była miastem wschodnim, dla Rosjan zaś - zachodnim. Trzecim typem pograniczności jest miejskość przeciwstawiona wiejskości. Rodząca się wszak nowoczesność najbardziej godziła w przebrzmiałą już wówczas wiejską kulturę szlachecką (s. 43-44). Miasto wytwarza zupełnie nowe sposoby życia, nową rytmikę pracy, spędzania wolnego czasu. Miejskość staje się też perspektywą, z której można spoglądać na wieś, widzieć ją inaczej. Chopin jako mieszkaniec miasta wakacje spędzał często poza miastem. Był jednak człowiekiem od kultury wiejskiej izolowanym. Determinowały go już inne czynniki egzystencjalne. Właściwie to wówczas stworzono tę funkcjonującą w polskiej literaturze, zwłaszcza poezji, antynomię urbanizmantyurbanizm. Rewersem perspektywy miejskiej było bowiem związane z wsią poczucie wyższości moralnej, które najczęściej manifestowano za pomocą obrazów miasta jako miejsca upadku obyczajów (s. 46). Faktem pozostaje, że miasto oferowało zupełnie inny sposób bycia jednostki ludzkiej. Kuziak wskazuje na znaczącą rolę, jaką zaczęły odgrywać w obrębie miast salony literackie i kawiarnie (s. 47). Były one swoistymi centrami rodzącej się na terenie Warszawy myśli. Pierwsze tego typu instytucje miały charakter elitarny, zwłaszcza jeśli chodzi o salony — w tym najsłynniejszy, uwieczniony w Dziadach cz. III przez Mickiewicza, arystokratyczny salon generała Wincentego Krasińskiego. Bardziej egalitarne były rzecz jasna kawiarnie, gdzie można było poczytać prasę oraz książki. W Warszawie jest już bowiem prasa, powstają instytucje kulturalne i oświatowe, 
jak powiada Kuziak, ,zastępują one dawną instytucję kultury, jaką był arystokratyczny dwór" (s. 49). W całej ciżbie wszelakich instytucji różnego autoramentu najważniejsze dla autora są wspomniane już salony i kawiarnie. Salony należały do miejsc, w których najczęściej rezydowali przedstawiciele klas wyższych, ale także konserwatyści kojarzeni z ruchem klasycystycznym. Rzadko pojawiali się w nich romantycy. Z punktu widzenia chopinowskich kontekstów istotna jest informacja, że często odbywały się w salonach występy muzyczne. Istotniejszy jednak dla dalszego rozwoju kultury nowoczesnej był rozwój życia kawiarnianego (s. 51). Bywał tam bowiem cały przekrój ludności miejskiej: „i młodzi, i starzy, studenci, gimnazjaliści, twórcy, dziennikarze, aktorzy i widzowie teatru" (s. 51). Bywał tam też Chopin.

W dalszej części pierwszego rozdziału Kuziak rozpatruje najważniejsze chyba bodaj pogranicze ówczesnej Warszawy, a zatem słynny konflikt między klasykami a romantykami. Był to spór pokoleniowy — starych z młodymi, lecz także spór o kształt polskiej nowoczesności. Można powiedzieć, że typ francuski, reprezentowany przez klasyków, został skonfrontowany z typami niemieckim i angielskim. Najważniejszą dla Kuziaka postacią tego wczesnego etapu polskiego romantyzmu był Kazimierz Brodziński - jako autor słynnej rozprawy O klasyczności i romantyczności tudzież o duchu poezji polskiej, opublikowanej w 1818 roku. Brodziński był nauczycielem Chopina, zaprzyjaźnionym z jego rodziną. Kuziak przywołuje postać Brodzińskiego, ponieważ był on autorem projektu tożsamościowego dla Polaków. Poeta podejmuje próbę pójścia trzecią drogą - między romantykami a klasykami. Autor bardzo szczegółowo omawia ten projekt, zwracając ponadto uwagę, że Brodziński także zajmował się muzyką, stale współpracując z Karolem Kurpińskim i Józefem Elsnerem, uprawiając ponadto działalność teoretycznomuzyczną. W duchu epoki wyrażał poglądy zbliżone do koncepcji korespondencji sztuk, podkreślając bliskość muzyki i poezji (s. 63). I co ciekawe, rozdzielenie tych sztuk na osobne byty uznawał Brodziński za znamię kultury nowoczesnej, której cechą jest dążenie do specjalizacji (s. 64).

Jak powiada Kuziak w dalszej części rozdziału: „Stosunek romantyków do nowoczesności i modernizacji jest skomplikowany i ambiwalentny” (s. 65). Sprzeciwiali się oświeceniowemu panowaniu rozumu, akceptowali jednak nowoczesność, rozumiejąc ją inaczej. Chodzi o większy partykularyzm, który sprzeciwiłby się uniwersalnej wersji nowoczesności — jednego przepisu dla wszystkich. Dlatego też istotną kwestią dla romantyków była oryginalność, indywidualizm, rodzimość, a przede wszystkim — odrębność narodowa. W pewnym sensie Warszawa była miastem, w którego obrębie ścierały się dwa oblicza nowoczesności: z jednej strony postoświeceniowej, z drugiej zaś romantycznej. Między nimi istniał jeszcze projekt Brodzińskiego, który starał się wyłuskać to, co z każdej strony sporu najlepsze dla nowego społeczeństwa, eliminując jednocześnie to, co wydawało mu się niepożądane. Kuziak do końca pierwszego rozdziału omawia wiele innych ciekawych postaci, tworzących intelektualny ferment ówczesnego miasta. 
Autor zmienia się w niezwykle drobiazgowego historiografa, rekonstruującego intelektualny panteon miasta. Jedna rzecz jednak umyka - Chopin nie istnieje przez większość tego rozdziału nawet jako widmo.

Drugi rozdział książki poświęca autor zjawisku instytucjonalizacji życia obywateli miast. Proces tworzenia różnych instytucji jest bardzo charakterystyczny dla nowoczesności. Chodzi wszak o zaspokajanie potrzeb, które rodzą się w środowisku miejskim. Instytucje mają więc charakter pragmatyczny i społeczny (s. 93). Jak powiada autor, I Rzeczpospolita była $\mathrm{w}$ istocie państwem pozbawionym instytucji, toteż nagła zmiana i przyspieszenie zmian cywilizacyjnych musiało się spotkać z oporem. Przykładem bardzo znaczącej polskiej instytucji, zwłaszcza w kontekście powstającej w Polsce nowej warstwy społecznej, a więc inteligencji, było Towarzystwo Warszawskie Przyjaciół Nauk, które powstało jako odpowiedź na germanizacyjne zapędy władz pruskich. Za misję instytucjonalną uznano wówczas kurs nowoczesności oświeceniowej przy jednoczesnym zacięciu patriotycznym (s. 99-100). Autor przez znaczną część rozdziału opowiada historię TWPN, podkreślając, jak istotną instytucją było ono w budowaniu polskiego modelu nowoczesności. Istniało jednak zbyt krótko, by na dobre zakorzenić swój model w polskim społeczeństwie. Inną istotną instytucją omawianą przez Kuziaka jest Biblioteka Publiczna prowadzona przez Samuela Bogumiła Lindego. Była ona wszak zalążkiem budowanej stopniowo biblioteki narodowej (s. 110). Działalność wymienionych instytucji była niezmiernie ważna, dlatego że umożliwiła zmianę mentalności ludzi, a przede wszystkim wytworzyła zapotrzebowanie na wykształcenie (s. 112). Stworzyło to warunki do rozwoju idei publicznej edukacji. Ważną instytucją edukacyjną stało się Liceum Warszawskie, które „wprowadziło nowoczesne, oświeceniowe zasady edukacyjne, ograniczając pamięciowy model nauki. Postawiło przed sobą zadanie kształcenia światłych obywateli - nauka była traktowana jako rodzaj Bildung, tworzenia pełnego człowieka" (s. 115). Chopin uczęszczał do Liceum Warszawskiego w latach 1823-1826. Dochodzi więc do rozwoju szkolnictwa publicznego, a także do utworzenia uniwersytetu. Chopin zaś od 1826 roku uczęszcza do Szkoły Głównej Muzyki, która powstała w tym samym roku jako jednostka uniwersytecka. Nowoczesny rozwój infrastruktury instytucjonalnej pozwolił zatem na znacznie swobodniejsze operowanie możliwościami zdobywania wykształcenia. Autor w dalszych partiach tekstu omawia działalność istotnych dla Chopina nauczycielu uniwersyteckich, zwłaszcza Ludwika Osińskiego, ponownie Kazimierza Brodzińskiego, a także Feliksa Bentkowskiego. Dalej omawia ponadto dzieje prasy, której instytucjonalnego charakteru nie można nie przecenić. W pewnym sensie pełniła ona funkcję komplementarną względem szkoły, albowiem ,zaznajamiała czytelników z tym, co działo się w europejskim świecie myśli i sztuki” (s. 157). To na łamach prasy ogłaszano występy młodego Chopina; to w prasie ukazał się pierwszy wiersz poświęcony kompozytorowi.

Rozdział trzeci poświęcony jest życiu intelektualnemu Warszawy. Autor stwierdza, że francuska kultura oświeceniowa była stopniowo wypierana przez 
kulturę niemiecką (s. 165). Podział ten ma charakter pokoleniowy: kultura francuska dotyczy warstw postoświeceniowych, niemiecka zaś — romantyków. Według Kuziaka polską nowoczesność typu romantycznego ukształtowała przede wszystkim filozofia niemiecka (s. 166-167). W dalszej części rozdziału Kuziak omawia krótko poglądy takich filozofów i poetów, jak Friedrich Schiller, August Wilhelm Schlegel czy Friedrich Wilhelm Joseph Schelling. Istotnym ogniwem intelektualnego fermentu był też tak zwany historyzm Johanna Gottfrieda Herdera (s. 169). Najwybitniejszym polskim myślicielem, który inspirował się myślą niemiecką, był Maurycy Mochnacki. Stworzył na tej podstawie, podobnie jak Brodziński, swoisty model polskiej tożsamości, coś na kształt „projektu rozwoju cywilizacyjnego Polski w czasach nowoczesnych" (s. 171). Kuziak drobiazgowo omawia dwa konkurencyjne projekty nowoczesnej tożsamości: z jednej strony Brodzińskiego, z drugiej - Mochnackiego. Osobny fragment pracy poświęca autor działalności krytycznej Mochnackiego. Był on wszak jednym z wybitniejszych krytyków muzycznych, a także zręcznym pianistą. Jego poglądy na muzykę zbiegały się z tymi, które reprezentował Brodziński. Wiązał ją bowiem z poezją (s. 175). Ponadto jego zasługi na polu krytyki muzycznej są nieocenione. Postrzegał bowiem muzykę semantycznie, dlatego też próbował tłumaczyć swoim czytelnikom znaczenie tego, co słyszeli (s. 176). Stworzył swoisty model krytyki muzycznej, którą łączył ze światopoglądem romantycznym.

Trzecia część książki kończy się rozważaniami autora nad fenomenami organizacji słowianofilskich, a także działalnością folklorystyczną, między innymi Oskara Kolberga, który przyjaźnił się z Chopinem. Dalej autor przybliża nam zjawisko mesjanizmu polskiego w wersji Jana Pawła Woronicza, który był zalążkiem późniejszych romantycznych mesjanizmów. Później dowiadujemy się wiele o polskim liberalizmie, którego pobieżną charakterystykę Kuziak przeprowadza, wymieniając takie postaci jak Dominik Krysiński czy Fryderyk Skarbek (s. 191192). W dalszej kolejności omawia autor zjawisko magnetyzmu, by przejść do części bodaj najbardziej interesującej, dotyczącej wszak muzycznych światopoglądów.

Na koniec niniejszej recenzji chciałbym odnieść się do problemu, który postawił Michał Kuziak w zakończeniu swojej książki. Zadał sobie bowiem pytanie, „w jakim stopniu Chopin skorzystał z możliwości kulturowych i intelektualnych, które rysowały się przed nim w Warszawie?" (s. 205). Odpowiada zdecydowanie wyłącznie w jednej kwestii — folkloru, który odbija się w twórczości kompozytora. Reszta problemów - jakże wielu przecież! — zostaje bez odpowiedzi. Autor nie stawia kwestii w sposób rozstrzygający; można powiedzieć, że raczej zachęca do namysłu. O czym jest więc książka Kuziaka? Czy o Chopinie? Czy o życiu Chopina? Wydaje się, że odpowiedź nie może być twierdząca ani w pierwszym, ani w drugim wypadku. Jest to książka o mieście, o instytucjach i o klimacie intelektualnym 20 lat życia Fryderyka Chopina. Kuziak w sposób znakomity zrekonstruował tło, po którym przechadza się wyłącznie cień. Nie jest to książka, 
w której Chopin występuje często. W trakcie lektury zdarza się, że wręcz o nim zapominamy; autor co jakiś czas jednakowoż subtelnie nam o jego obecności przypomina.

Wielka szkoda, że nie pojawiły się w omawianej pracy wątki związane z nowoczesnym postrzeganiem dźwięku, a także zalążkach nowoczesnej kultury słuchania akuzmatycznego, które przypuszczalnie pojawiły się już w czasach Chopina, zwłaszcza w obrębie przestrzeni salonu, który pełnił ówcześnie funkcję

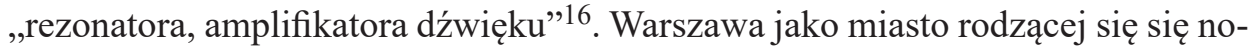
woczesności była także miejscem tworzenia się nowego trybu słuchania muzyki, a także doświadczania dźwięku w ogóle. Nowoczesność przyniosła ponadto inny tryb zarządzania dźwiękiem, który w różnej postaci stawał się jednym z możliwych narzędzi sankcjonowanej państwowo przemocy ${ }^{17}$. Myślę, że dobrym dopełnieniem książki, zwłaszcza zaś fragmentów mówiących o rodzącej się kulturze salonu oraz kawiarni literackiej, byłaby refleksja poświęcona z jednej strony nowym sposobom aplikacji dźwięku, determinowanego przez nowoczesne środowisko miejskie; z drugiej zaś — refleksja nad tym, do jakiego stopnia coraz głośniejsza audiosfera nowoczesnego miasta kiełznana jest przez stosunek władzy zaborczej nad obywatelami. Nowoczesność jako zjawisko powiązane z kulturą miejską diametralnie zmieniła jakość środowiska dźwiękowego; jeśli zaś zgodzić się z Kuziakiem, że najbliższe otoczenie nie pozostaje bez wpływu na człowieka, warto zastanowić się także i nad tym aspektem Warszawy Chopina. Omawiana książka dotyczy jednak ,pejzażu myśli”, nie zaś „pejzaży dźwiękowych”. Jest ona cenną skarbnicą wiedzy na temat Warszawy, pigułką na temat rodzącej się w Polsce nowoczesności, a także znakomitym wykładem myśli wielu wybitnych polskich uczonych i filozofów. Jej niewątpliwą zaletą jest to, że może pełnić kompendium wiedzy i zasadniczy punkt startowy dociekań badawczych. Rekonstrukcja świata, po którym stąpał i w którym żył i dorastał Fryderyk Chopin, zdecydowanie się Michałowi Kuziakowi udała.

16 Jak pisze Maciej Janicki: „w salonie słuchacze improwizacji Chopina ledwie dostrzegają artystę i współsłuchaczy o nieobecnych, zawieszonym wzroku albo twarzach zasłoniętych dłonią. Słuchaj niemal akuzmatycznie, koncentrując się na dźwięku samym w sobie, abstrahując częściowo przynajmniej od jego źródła/wykonawcy". Por. M. Janicki, Mikroskop dla uszu. O XIX-wiecznym stuchaniu Chopina, „Audiosfera” 2015, nr 1, s. 47-48.

17 Janicki powiada, że w 1826 roku prowadził bujny kawiarniany tryb życia, wypełniony po brzegi feeriami różnych dźwięków — nie tylko muzyki, lecz też audio- i fonosfery miejskiej. Wraz ze zmianą trybu życia po wstąpieniu do Szkoły Głównej Muzyki oraz restrykcjami politycznymi doszło do „wyciszenia” trybu życia. Według Janickiego może to świadczyć o tym, do jakiego stopnia cisza „komunikuje stosunki władzy”. Por. M. Janicki, Polityka i grajace tabakierki. Chopin a fonosystem, „Prace Komisji Krajobrazu Kulturowego” 2008, nr 9, s. 241. 


\section{BIBLIOGRAFIA}

Adamusińska-Tasak A., Scena warszawska oczami Fryderyka Chopina, Warszawa 2018.

Chomiński J.M., Chopin, Kraków 1978.

Czapliński C., Śladami Chopina w Warszawie i na Mazowszu, Płock 2010.

Dziadek M., O polskich biografiach Chopina w XIX wieku, Warszawa 2019.

Fabianowski A., Sonata Norwidowska, Warszawa 2019.

Fabianowski A., Towarzystwo Iksów, Warszawa 2019.

Frączyk T., Warszawa młodości Chopina, Kraków 1961.

German F., Chopin i literaci warszawscy, Kraków 1960.

German F., Muzycy warszawscy okresu młodości Chopina, Katowice 1977.

Goldberg H., O muzyce w Warszawie Chopina, przeł. M. Albán Juárez, K. Stępień-Kutera, Warszawa 2016.

Hoesick F., Chopin. Życie i twórczość, t. 1. Warszawa 1810-1831, Warszawa 1910.

Hoesick F., Warszawa. Luźne kartki z przeszłości Syreniego Grodu, red. M. Karpińska, Warszawa 2020.

Janicki M., Mikroskop dla uszu. O XIX-wiecznym stuchaniu Chopina, „Audiosfera” 2015, nr 1.

Janicki M., Polityka i grajace tabakierki. Chopin a fonosystem, „Prace Komisji Krajobrazu Kulturowego" 2008, nr 9.

Jeżewska Z., Warszawskim szlakiem Chopina, Warszawa 1979.

Kowalczykowa A., Warszawa romantyczna, Warszawa 1987.

Kowalska A., Warszawa literacka w okresie przełomu kulturalnego 1815-1822, Warszawa 1961.

Kuziak M., Romantyzm i nowoczesność?, [w:] Romantyzm i nowoczesność, red. M. Kuziak, Kraków 2009.

Lissa Z., Studia nad twórczością Fryderyka Chopina, Kraków 1970.

Michalska K., Kuziak M., Warszawa czasów Chopina byta wyspa nowoczesności, https://www. polskieradio.pl/8/3664/Artykul/2727860,Prof-Michal-Kuziak-Warszawa-czasow-Chopina-byla-wyspa-nowoczesnosci.

Miziołek J., Kowalski H., Uniwersytet Warszawski i młody Chopin, Warszawa 2013.

Miziołek J., Śladami Chopina po Uniwersytecie Warszawskim. 200-lecie urodzin geniusza fortepianu (1810-2010), Warszawa 2010.

Mysłakowski P., Warszawa Chopinów. Warszawskie adresy Chopinów na podstawie źródet ustalone, oprac. kartogr. P.E. Weszpiński, Warszawa 2012.

Mysłakowski P., Sikorski A., Fryderyk Chopin. Korzenie, Warszawa 2009.

Niewiarowska B., Warszawa Fryderyka Chopina, wstęp K. Mórawski, W. Młotkowski, Warszawa 2010.

Opieński H., Czy Chopin jest romantykiem?, „Chopin” 1937, $\mathrm{nr} 2$.

Prosnak J., Fryderyk Chopin. Żelazowa Wola. Warszawa, Warszawa 1977.

Rydel L., Warszawa i jej dzieje kulturalne i wojenne, Kraków 1915.

Siemieński J., Warszawa $w$ dziejach Polski, Warszawa [ok. 1929].

Spacer „Z Chopinem po Warszawie”, https://culture.pl/pl/artykul/spacer-z-chopinem-po-warszawie.

Warszawa miasto Chopina, red. Z. Jachimecki, M. Idzikowski, J. Siwkowska, S. Szwankowski, Warszawa 1950.

Wąsowski M., Fryderyk w Pałacu, Warszawa 2018.

Wóycicki K.W., Kawa literacka w Warszawie (r. 1829-1830), Warszawa 1873.

Wóycicki K.W., Warszawa i jej społeczność w początkach naszego stulecia, Warszawa 1875. 


\section{A spectre of Chopin is haunting Warsaw}

\section{Summary}

Pejzaż myśli. Warszawa Chopina i początek polskiej nowoczesności [A landscape of thoughts: Chopin's Warsaw and the beginning of Polish modernity] by Michał Kuziak is a book combining the values of a scholarly work and a work whose main task is to popularise knowledge both about Frédéric Chopin himself and about the world that surrounded him and that shaped him. The dissertation is not only the context for the composer>s life; it is also part of a broader stream of research on the beginnings of Polish modernity. The book is therefore about Warsaw understood not only as the place where young Frédéric grew up, but also as the area where the foundations of Polish modernity were laid. Chopin functioned in a kind of intellectual melting pot within which there was a conflict between tradition and modernity, between progress and conservatism. The author precisely delineates the chronological framework within which he moves. These are the years 1810-1830, that is, the first 20 years of the composer's life. However, the book does not only focus on the person of Chopin, so it is not "Chopin-centric." The work consists of three parts, each of them marked with a significant title: 1. "City and people"; 2. "Institutions and people"; 3. "Thoughts and people." This arrangement is a good example of the author's main idea: to show Chopin among people, and also people within the city, municipal institutions and the thoughts that developed there. For the author of the book, Warsaw was a crucible and a cosmos of thoughts: on the one hand, there is a constant offensive of scientific and technical thought related to the Enlightenment tradition, and on the other, the birth of the world of spirit and religion. Polish modernity is an eclectic mixture in which there are still remnants of the noble world, but the foundations of the bourgeois world are also being laid. Kuziak, drawing an image of Warsaw at that time, emphasises the importance of key cultural institutions, such as literary salons and cafés. For Chopin, cafés, where he met with representatives of the contemporary world of literature and poetry, were of particular importance. Warsaw's intellectual climate, inspired by the French Enlightenment, was giving way more and more to the influences of German culture associated with Romanticism. Kuziak writes that the modernity of the Romantic type was shaped by German culture. He regards the considerations of Kazimierz Brodziński and Maurycy Mochnacki as the two largest projects of modern Polish identity. Importantly, both of these authors were closely associated with the Polish musical culture which the young Chopin absorbed. The author of the book makes a reservation that it is difficult to conclusively confirm what influence the institutional and intellectual shape of Warsaw at that time had on Chopin. He states with certainty that Chopin's trips outside the city, and thus getting to know Masovian folklore, had a decisive impact on his imagination. The book does not, however, determine how the then Warsaw shaped the composer's later life. The author brilliantly reconstructed the background on which Chopin's shadow moved, but he chose not to answer the most important question: did the city, people, institutions and intellectual climate ultimately form the composer's modern world view? This question remains open.

Keywords: Frédéric Chopin, Warsaw, modernity, 1810-1830, music, literature 